\title{
iglesia en Royan
}

G. GILLET, arquifecto

$148-71$

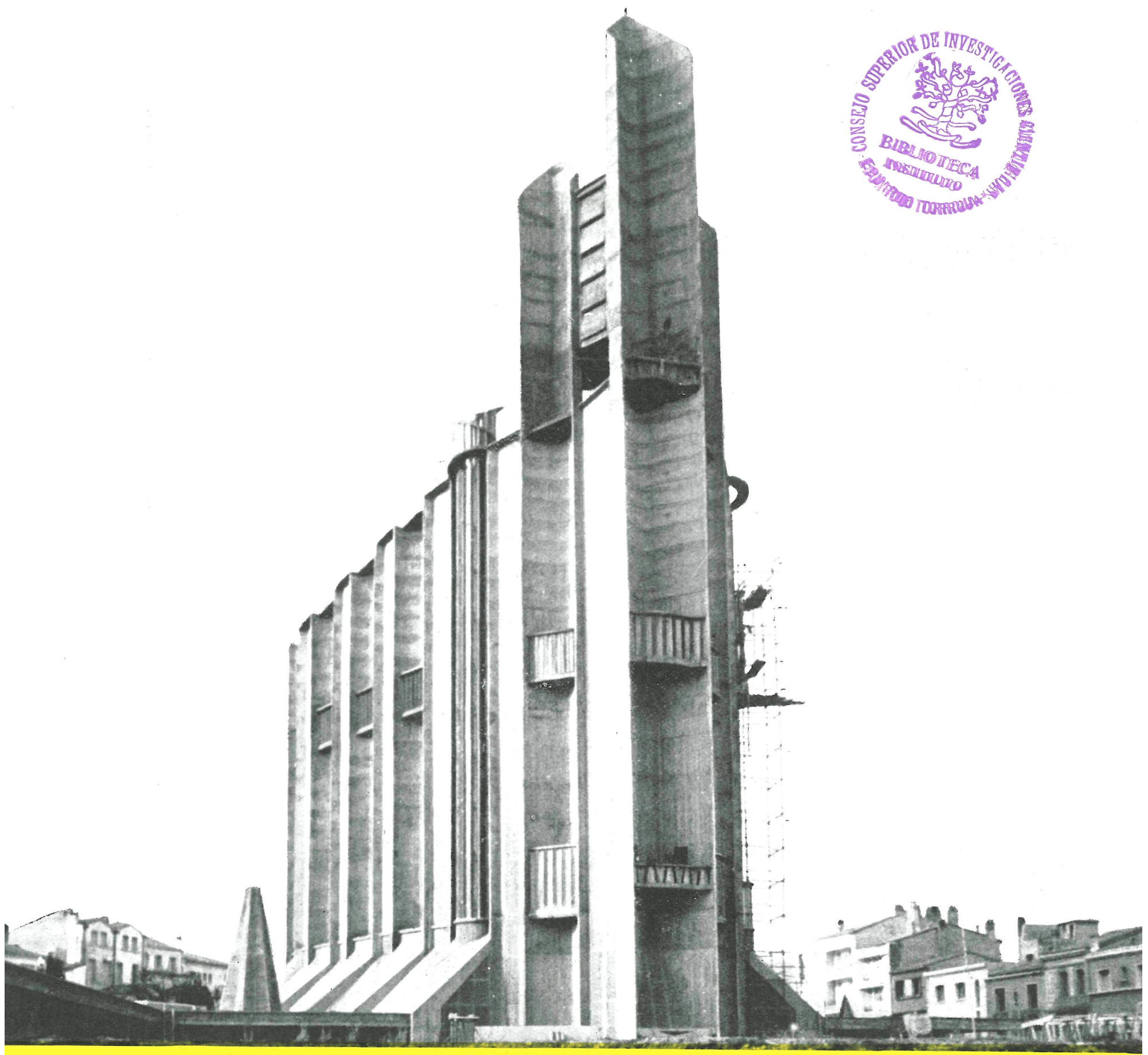




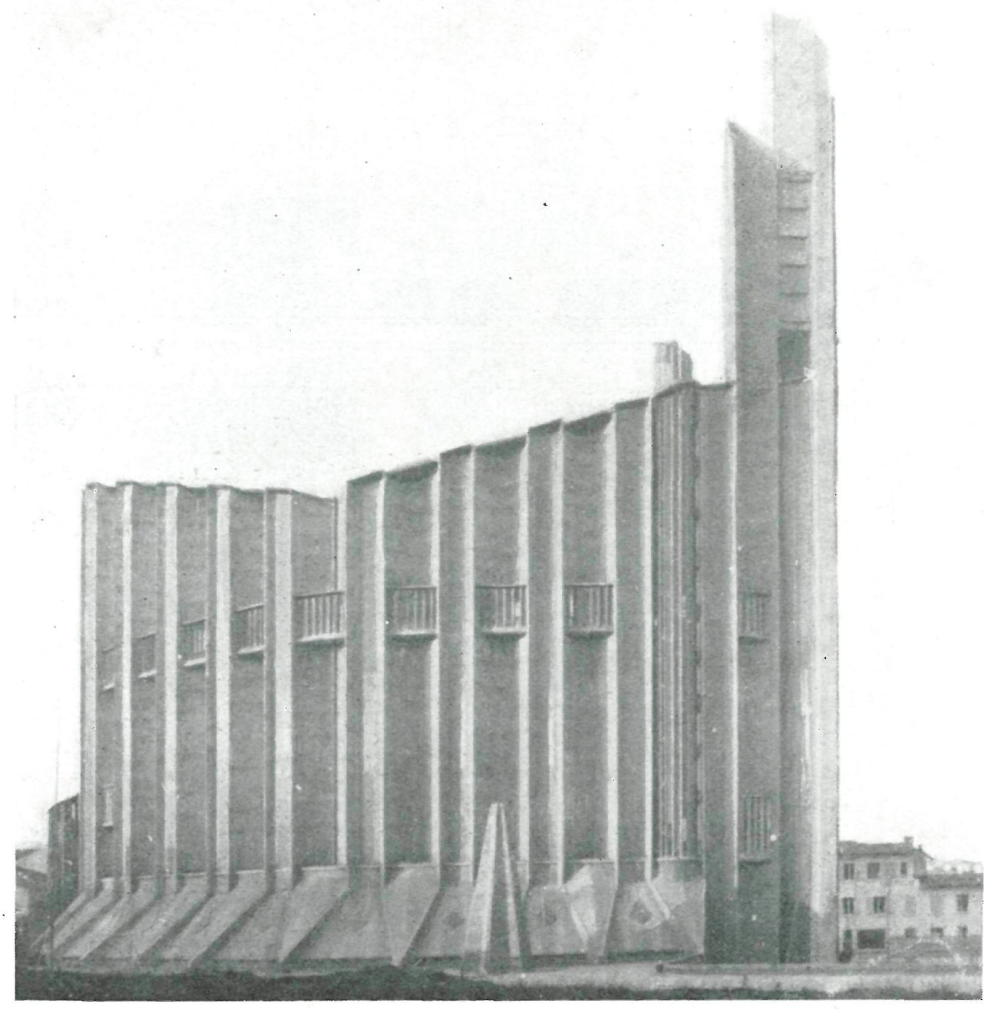

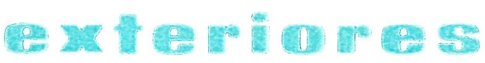

En el número 92 de nuestra Revista se publicó esta iglesia, cuando todavía las obras estaban en su fase inicial. Ahora, una vez terminada, insistimos nuevamente, por considerarlo de verdadero interés, desde el punto de vista estructural, en cuanto al adecuado empleo del hormigón armado, y por estar concebida de manera evidentemente original y notable.

La iglesia está emplaza en un terreno triangular con grandes desniveles, y la ordenación arquitectónica ha nacido de las necesidades del programa establecido. Su planta está compuesta por dos grandes parábolas, que se cortan simétricamente en la parte más ancha de la nave.

La entrada principal está situada a cuatro metros sobre el nivel de dicha nave, cerrada por el coro, sobre el que se elevan las tres agujas del campanario.

Los dos altares-interior y exterior-se hallan enfrentados y dispuestos de tal forma que puedan servir a los fieles que asisten a la Santa Misa desde dentro y desde fuera de la iglesia. 


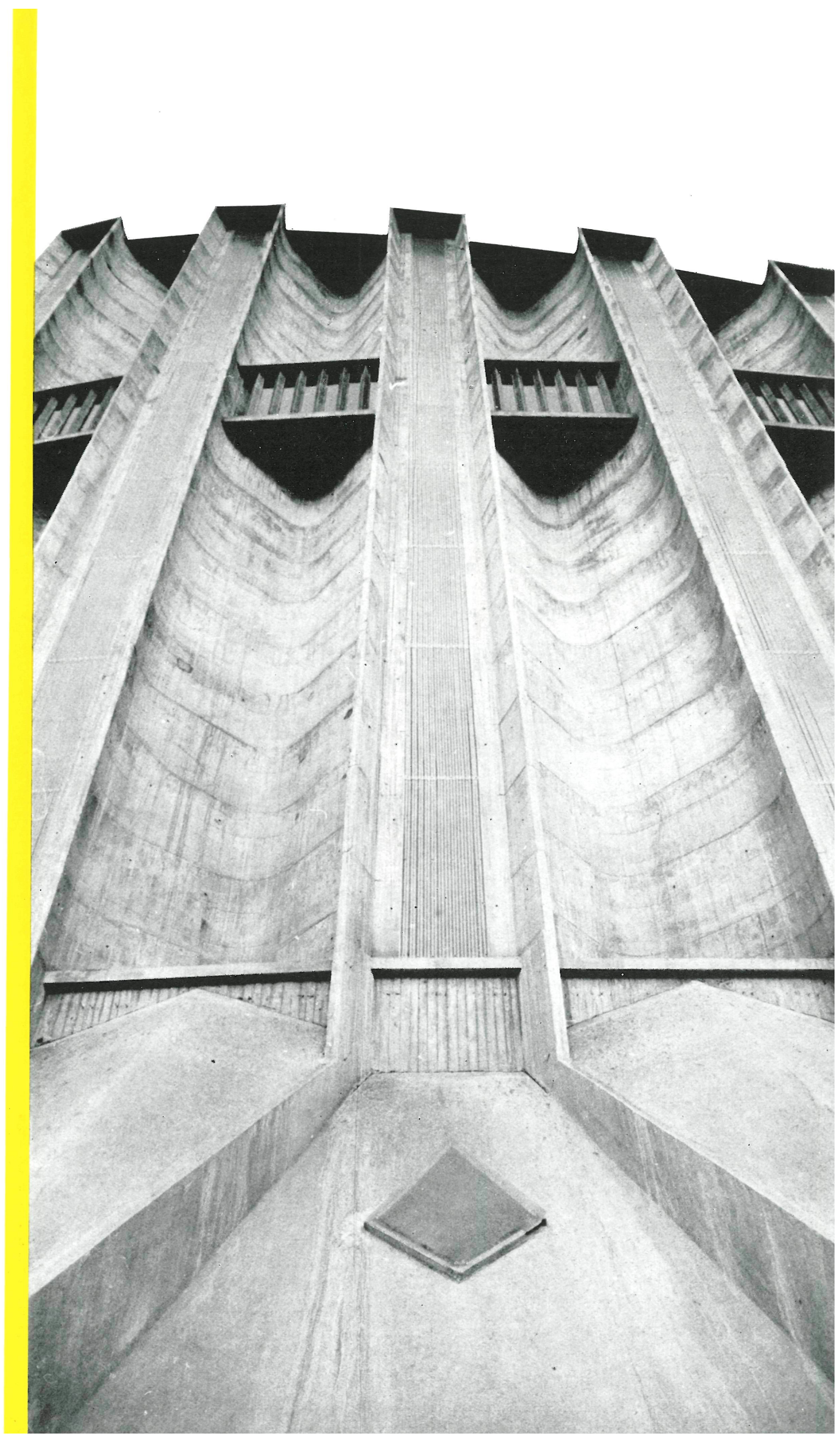


La envolvente volumétrica de esta planta original está constituída por elementos constructivos de la más avanzada técnica, a base de láminas delgadas de hormigón armado en los elementos verticales sustentantes - de $10 \mathrm{~cm}$ de espesor y mas de $30 \mathrm{~m}$ de alturay en la cubierta, de doble curvatura y $8 \mathrm{~cm}$ de espesor, extendida entre los arcos de borde que forman la cornisa.

Los elementos de fachada, con planta en $\mathrm{V}$, apoyan en su "nariz» por medio de una rótula, confiando su estabilidad a los con trafuertes articulados, en semi-pórtico, que cubren y constituyen los pasillos laterale de circuren de circunvalación. Estos soportes fueron calculados por el ingeniero B. Lafaille, continuando su estudio y desarrollo, a la muerte de aquél, su colaborador, el ingeniero $R$. Sarger.

En el baptisterio se repite nuevamente la técnica de la lámina plegada y cortada en bisel en su base.

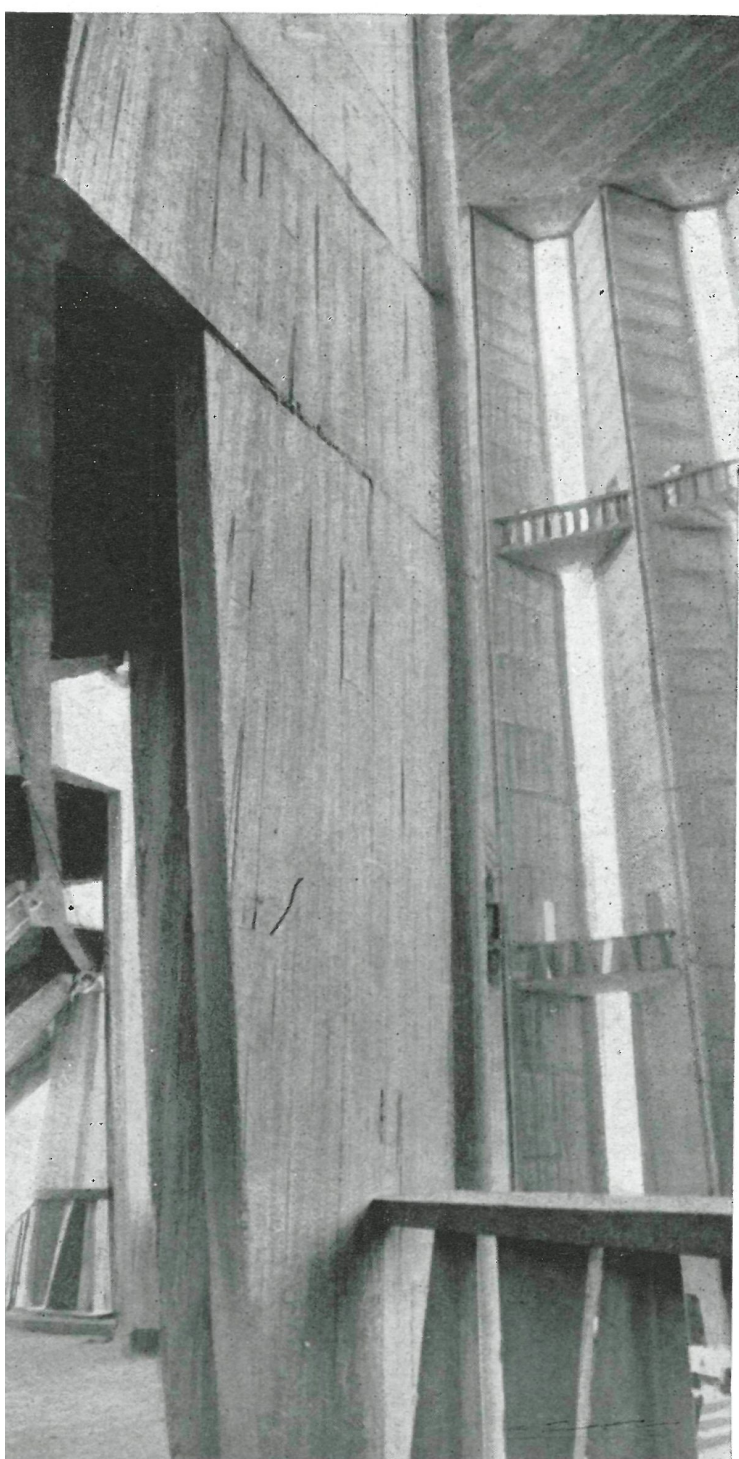

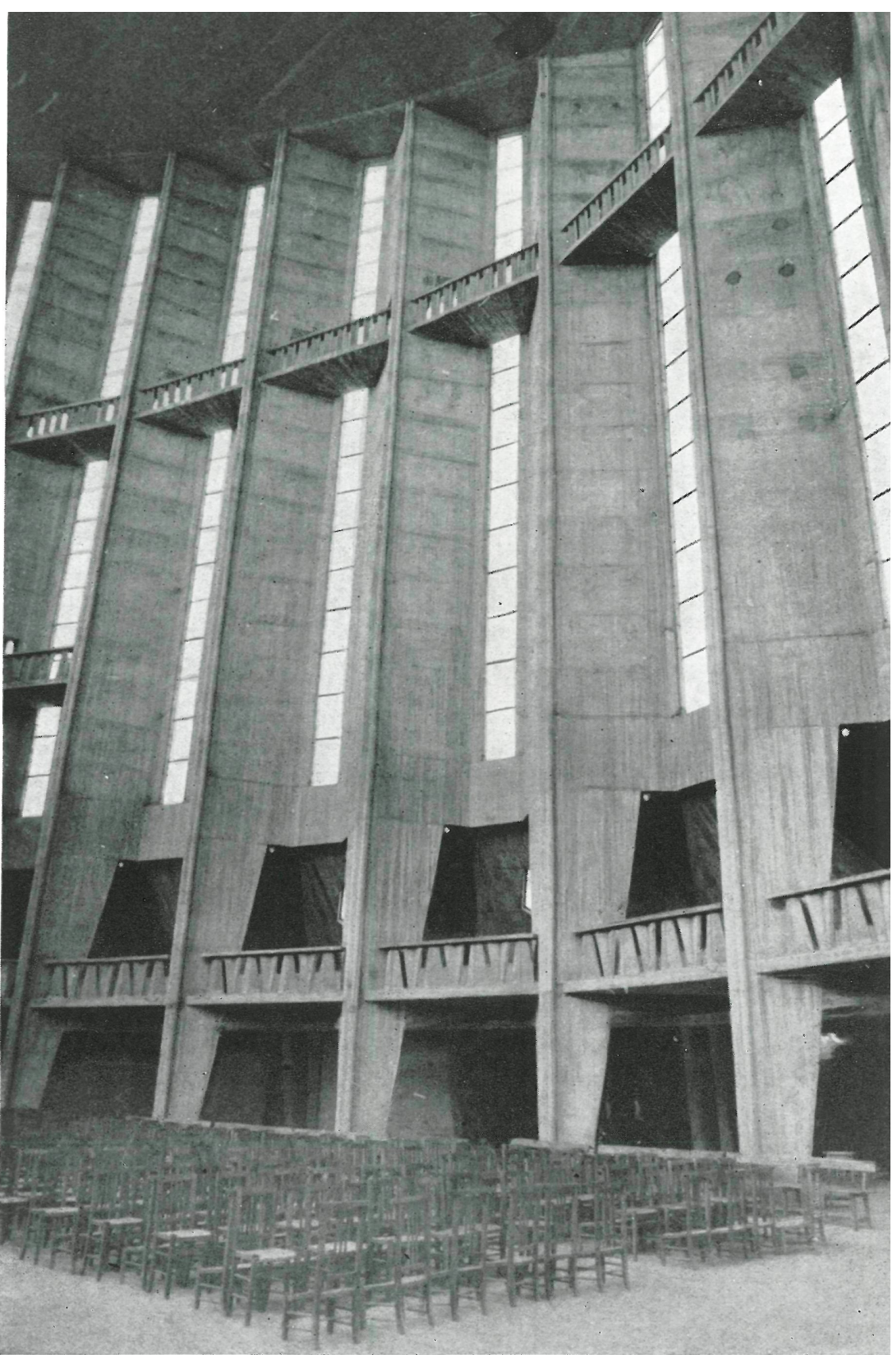

Hay que destacar la existencia de las dos coronas horizontales que zunchan el edificio a diferentes alturas formando dos galerias, y que transmiten los esfuerzos ocasionados por la acción del viento a las $\mathrm{V}$ principales importantes que flanquean, por una parte, el coro, y por la otra, el porche de entrada. Estos últimos elementos, enlazados dos a dos por las tribunas altas, constituyen los grandes pórticos estabilizados.

La utilización, clara y expresiva de elementos estructurales, con un espiritu voluntariamente descarnado-hormigón visto-, ha permitido crear una unidad arquitectónica de grandeza monumental y severa, origen posible de un adquiriendo forma y medida, van creciendo hacia el cielo y atestiguan su función y declaran el contenido que encierra.

La iluminación, marcadamente vertical, por cristaleras alargadas en los vértices de las $\mathrm{V}$ laterales, acusa más todavía la grandeza interior del conjunto. 


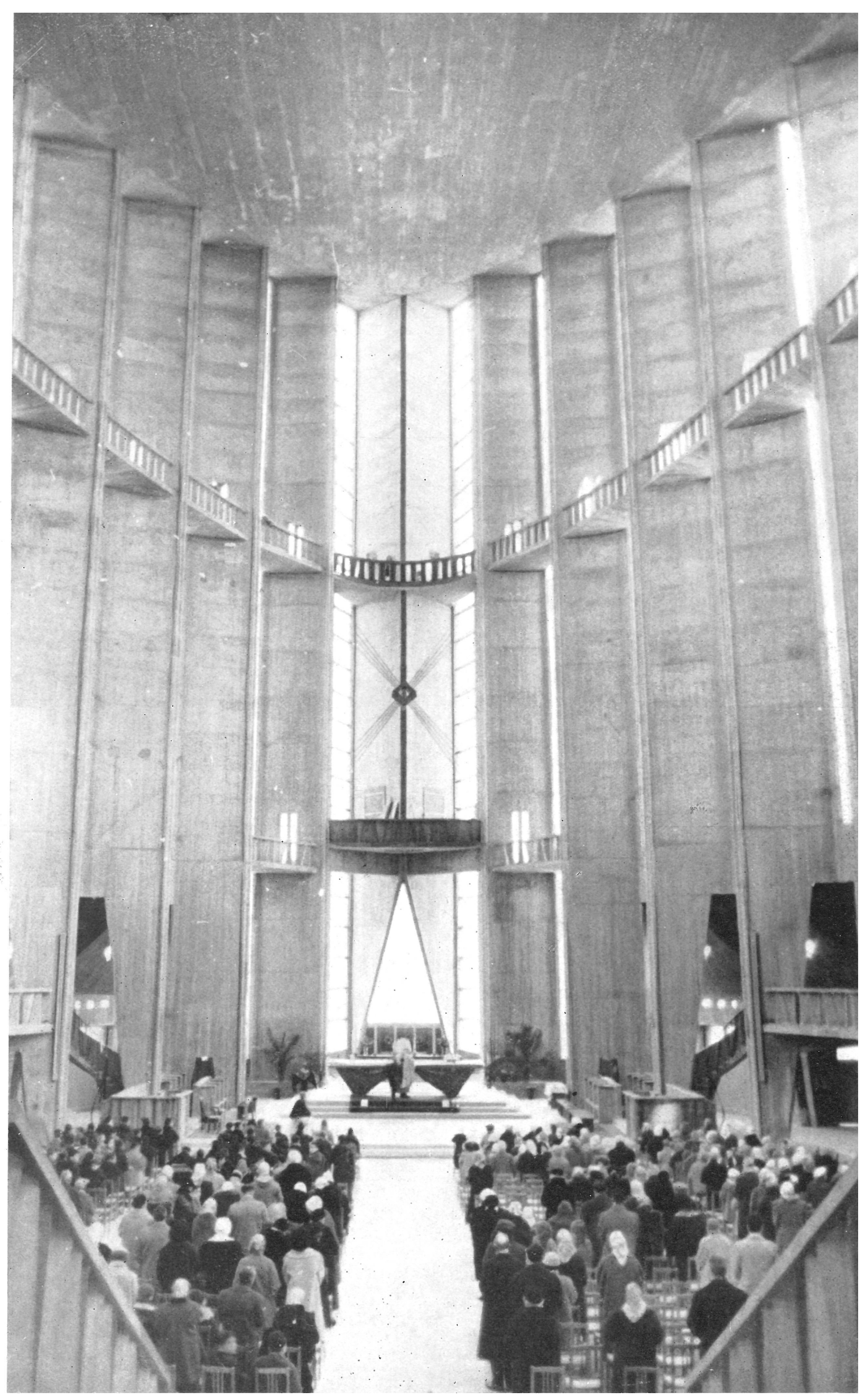


detalles del cerramiento y cubierta
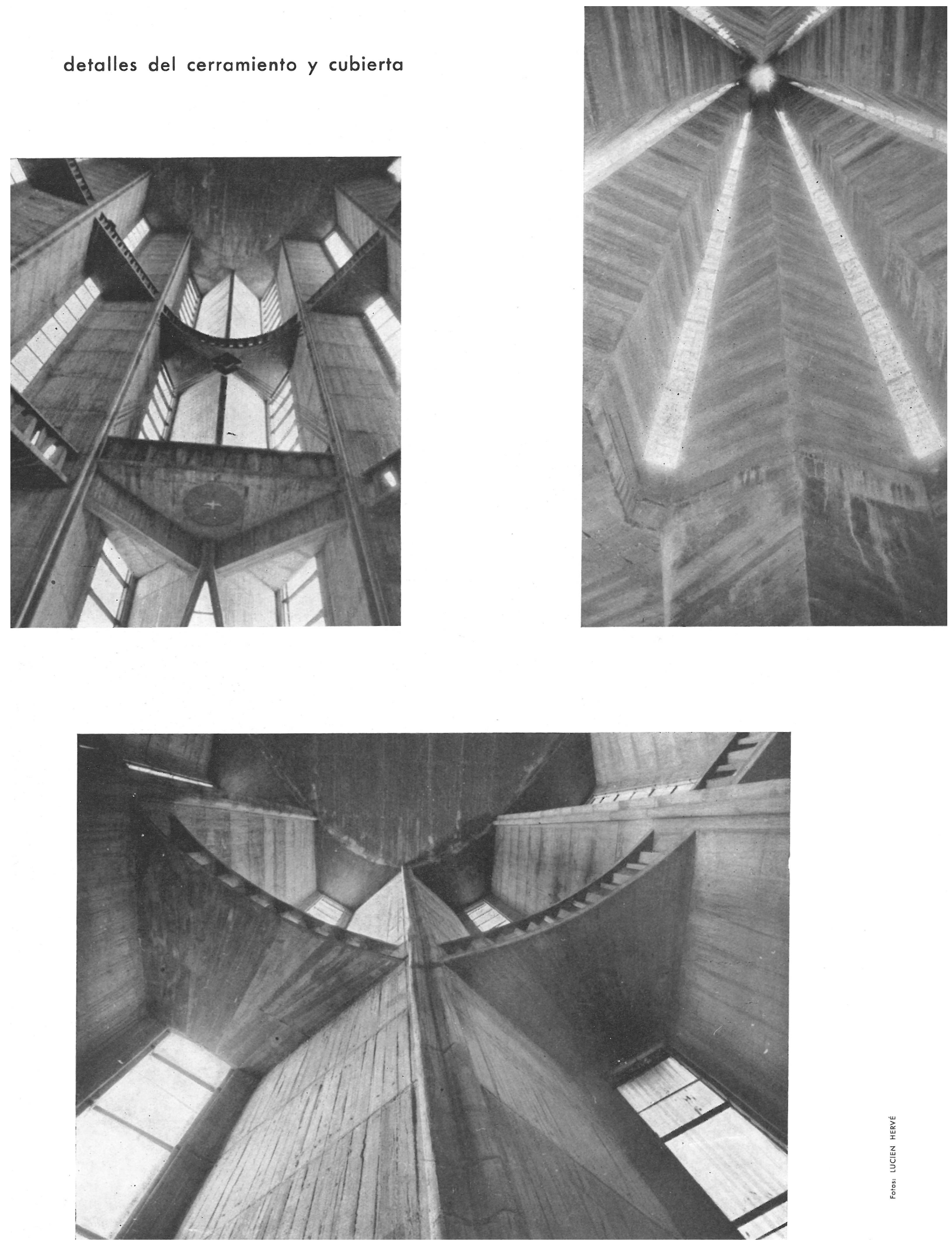